\section{Endoscopic ultrasound-guided jejunogastrostomy to perform endoscopic cholangiography in a patient with a modified Roux-en-Y hepaticojejunostomy}
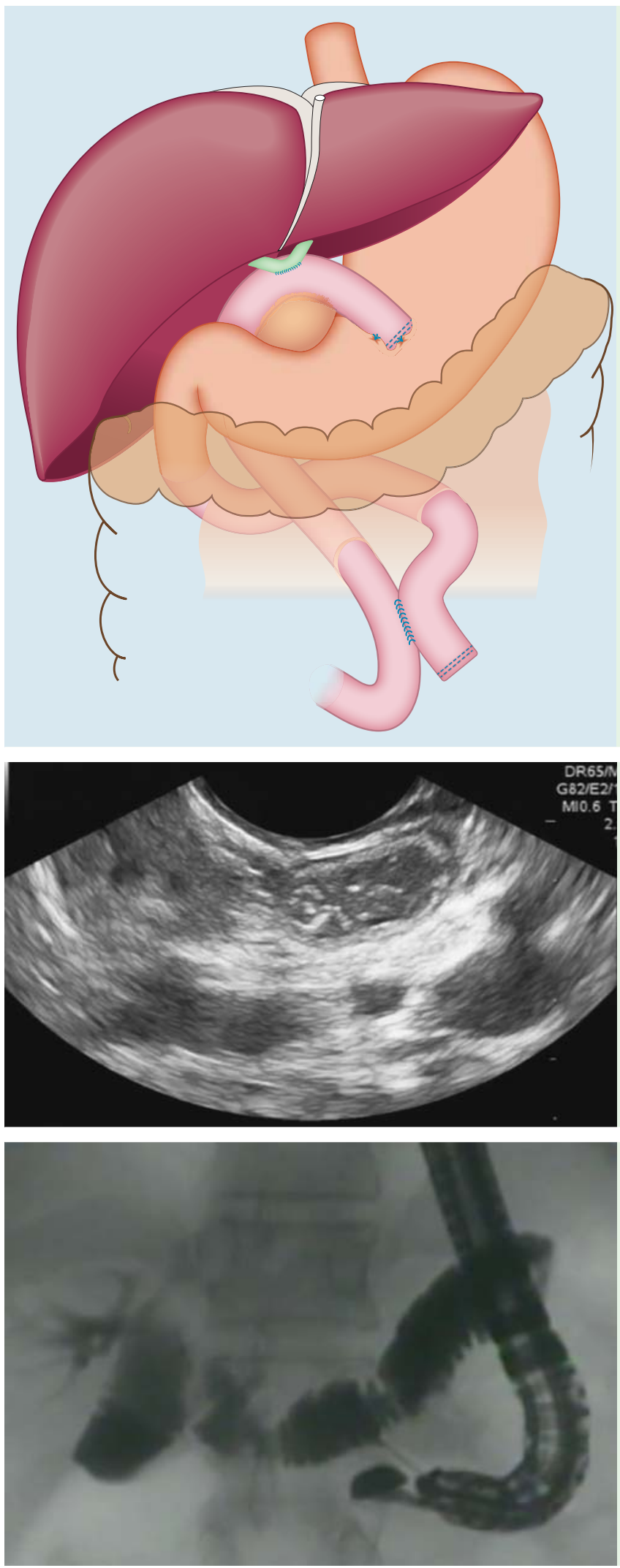

Fig. 1 Schema of modified Roux-en-Y hepaticojejunostomy.

Fig. 2 Endoscopic ultrasound (EUS) view of the jejunal loop beside the stomach, in a patient who had previously undergone a modified Roux-en-Y hepaticojejunostomy.

Fig. 3 lodine contrast inside the jejunal loop, after endoscopic ultrasound (EUS)-guided transgastric needle injection and creation of a jejunogastrostomy.
A 43-year-old woman had been diagnosed with intrahepatic duct stones and referred in 2007 for cholecystectomy and modified Roux-en-Y hepaticojejunostomy. A jejunal loop had been fixed to the anterior wall of the stomach for future endoscopic access, if necessary ( Fig. 1 ). The patient had remained asymptomatic for 5 years, but then presented with multiple episodes of cholangitis. Magnetic resonance cholangiography in 2012, showed intrahepatic duct stones. Conventional endoscopic retrograde cholangiopancreatography (ERCP) failed. Thus a decision was taken to perform endoscopic extraction of the biliary stones by accessing the jejunal loop, guided by endoscopic ultrasound (EUS).

The procedure was performed using a linear echoendoscope (Pentax Corporation, Japan). The jejunal loop adjacent to the anterior stomach wall was identified (๑ Fig.2). A 19-G needle (EchoTipUltra; Wilson-Cook, Winston-Salem, North Carolina, USA) was inserted transgastrically into the loop under EUS guidance. Iodine contrast was injected confirming adequate positioning of the needle inside the loop ( Fig.3). A 0.035-inch guidewire (Jagwire; Boston Scientific, Massachusetts, USA) was advanced through the needle into the loop. A jejunogastrostomy was then created using a 10-Fr cystotome (Cystotome; Wilson-Cook, North Carolina, USA), and the tract was enlarged using a $10 \mathrm{~mm} \times 4 \mathrm{~cm}$ biliary balloon dilation catheter (Hurricane RX; Boston Scientific, Boston, USA). A 9.8-mm gastroscope was then introduced through the jejunogastrostomy and into the jejunal loop. It was possible to reach the hepaticojejunostomy ( $\bullet$ Fig.4) and to perform direct cholangioscopy and endoscopic cholangiography. Using a 8.5/12/15-mm extraction balloon (Fusion; Wilson-Cook) it was possible to remove sludge and small stones from the bile ducts ( $\bullet$ Fig.5). In order to maintain patency of the jejunogastrostomy for further endoscopic access into the biliary ducts, we opted to place three 10-Fr double-pigtail plastic stents (Biliary Stent Set; Wilson-Cook) ( $\bullet$ Fig.6).

The patient recovered well, and at 1 -year follow-up she has remained asymptomatic without further episodes of cholangitis. Currently the plastic stents are still in place, and a further magnetic resonance cholangiography will be done.

Endoscopy_UCTN_Code_TTT_1AS_2AD 

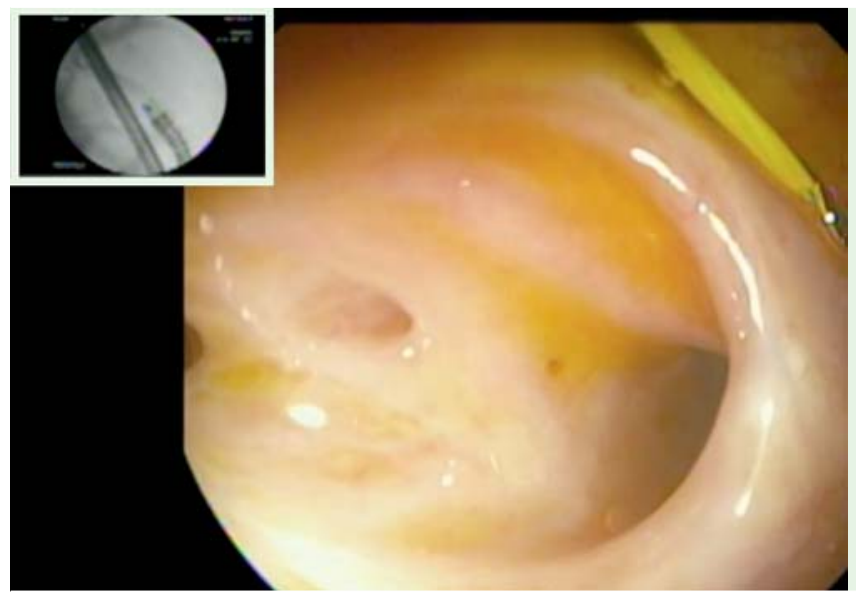

Fig. 4 Endoscopic view of the hepaticojejunostomy.
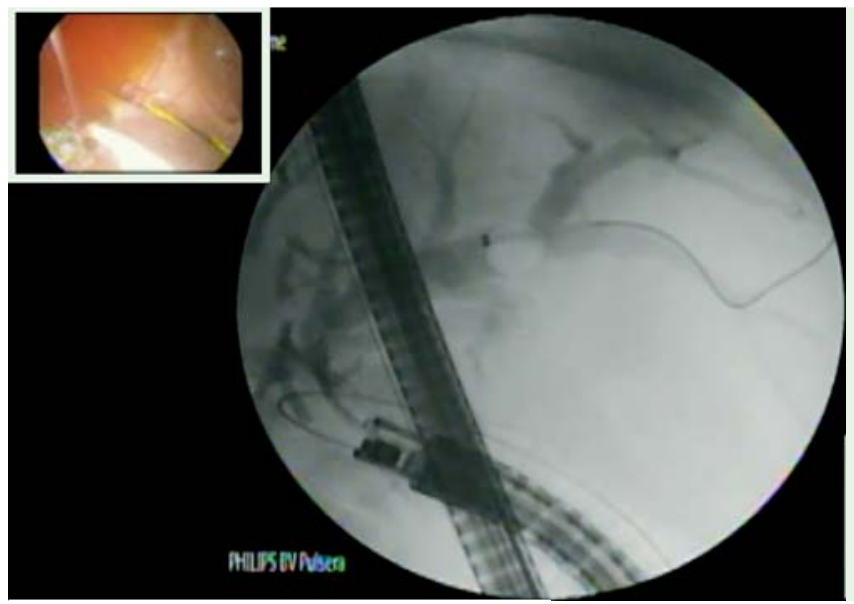

Fig. 5 lodine contrast and extraction balloon inside intrahepatic ducts. Sludge and small stones were removed.
Rogério Colaiacovo ${ }^{1}$, Augusto P. C. Carbonari ${ }^{1}$, Lucio G. Rossini ${ }^{1}$, Andre de Moricz ${ }^{2}$, Erwin Santo ${ }^{3}$, Marc Giovannini ${ }^{4}$

${ }^{1}$ Department of Endoscopy and FrenchBrazilian Centre of Endoscopic Ultrasound (CFBEUS), Santa Casa de São Paulo Hospital, São Paulo, Brazil

2 Department of Surgery, Santa Casa de São Paulo Hospital, São Paulo, Brazil

${ }^{3}$ Department of Gastroenterology and Liver Diseases, Tel Aviv Sourasky Medical Center, Tel Aviv, Israel

${ }^{4}$ Department of Gastroenterology and Endoscopy, Paoli Calmettes Institute, Marseille, France

Bibliography

Dol http://dx.doi.org/

10.1055/s-0034-1390923

Endoscopy 2014; 46: E680-E681

(c) Georg Thieme Verlag KG

Stuttgart · New York

ISSN 0013-726X

\section{Corresponding author}

\section{Augusto Carbonari, MD}

Department of Endoscopy and French-Brazilian

Centre of Endoscopic Ultrasound (CFBEUS)

Santa Casa de São Paulo Hospital

Rua Manuel Figueiredo Landim 600 ap. 52A

São Paulo 04693-130

Brazil

Fax: +55-19-996040645

augustocarbonari@gmail.com 